\title{
Percepção ambiental rural de estudantes do ensino fundamental em escolas do
}

\section{Município de Ijui-RS}

\author{
Environmental rural perception of students of elementary education in schools of the Municipality
} of Ijui-RS

Percepción ambiental de estudiantes de escuelas primarias rurales en la Ciudad de Ijui-RS

Luana Carvalhaes Coutinho

ORCID: https://orcid.org/0000-0001-5780-3195

Universidade de Cruz Alta, Brasil

E-mail: luana14carvalhaes@ hotmail.com

André Schoffel

ORCID: https://orcid.org/0000-0002-2501-4834

Universidade de Cruz Alta, Brasil

E-mail: aschoffel@unicruz.edu.br

Juliane Nicolodi Camera

ORCID: https://orcid.org/0000-0001-7182-5788

Universidade de Cruz Alta, Brasil

E-mail: jcamera@unicruz.edu.br

Diego Pascoal Golle

ORCID: https://orcid.org/0000-0002-5264-8007

Universidade de Cruz Alta, Brasil

E-mail: dgolle@unicruz.edu.br

Jordana Luisa Broch

ORCID: https://orcid.org/0000-0001-8366-7596 Universidade de Cruz Alta, Brasil

E-mail: brochjordanaluisa@gmail.com

Michele Ferraz Figueiró

ORCID: https://orcid.org/0000-0002-6996-0048

Universidade Federal de Santa Maria, Brasil

E-mail: mferrazfigueiro@gmail.com

Jana Koefender

ORCID: https://orcid.org/0000-0002-5882-9669

Universidade de Cruz Alta, Brasil

E-mail: jkoefender@unicruz.edu.br

\begin{abstract}
Resumo
Entende-se que o conhecimento e a compreensão das percepções de estudantes em relação ao ambiente em que vivem e como interagem com o mesmo é fundamental para orientação de práticas em educação ambiental. Objetivou-se nesta pesquisa compreender a percepção ambiental de estudantes que frequentam escolas localizadas em ambiente rural; quanto ao efeito do agrotóxico no ambiente e seu reflexo na saúde humana. O estudo foi realizado em duas escolas do Ensino Fundamental do interior do Município de Ijuí, Rio Grande do Sul, no período de março a julho de 2018, com a participação de 20 alunos por escola. A pesquisa foi descritiva, de cunho qualitativo pautada na narrativa dos estudantes, por meio da realização de uma entrevista semiestruturada, tendo como critérios de inclusão ser filho de agricultor e/ou morador no meio rural. Integrou-se à interpretação a análise de conteúdo e, por meio de mineração de texto, o conteúdo foi hierarquizado com auxílio do software IRaMuTeQ. As análises neste estudo foram: distribuição de frequência de palavras, frequência de palavras segundo os fatores: filhos de agricultores; uso de agrotóxico e gênero; nuvem de palavras e análise de similitude. Ficou evidenciado que a maioria pretende migrar para a cidade no intuito de frequentar o ensino superior e buscar alternativas de trabalho e renda. O uso de agrotóxico nas propriedades e casos de intoxicação foram mencionados. Verificou-se que a percepção de aspectos que envolvem o ambiente difere em virtude da realidade de cada indivíduo, assim como entre as séries avaliadas.
\end{abstract}

Palavras-chave: Percepção; Educação ambiental; Agricultura ecológica; Ensino.

\section{Abastract}

It's understood that the knowledge and understanding of the students' perceptions regarding the environment in which they live and how they interact with it's fundamental for guiding practices in environmental education. Thus, the objective of this research was to understand the environmental perception of students that attend schools located in rural environment as to the effect of the pesticide on the environment and its reflex on human health. The study was 
accomplished in two primary schools located in the municipality of Ijuí, Rio Grande do Sul, from March to July 2018, with the participation of 20 students per school. The research was descriptive, of a qualitative nature based on the students' narrative, through the accomplishment of a semi-structured interview, having the criteria of inclusion being son of a farmer and/or a resident in rural areas. Content analysis was integrated into the interpretation and, through text mining, the content was hierarchized using the IRaMuTeQ software. The analyzes in this study were: frequency distribution of words, frequency of words according to the factors: children of farmers; use of pesticides and gender; word cloud and similarity analysis. It was evidenced that the majority intends to migrate to the city in order to attend higher education and search alternative forms of work and income. The use of pesticides in properties and cases of intoxication were mentioned. In this way, it was verified that the perception of aspects that involve the environment differs in virtue of the reality of each individual, as well as between the evaluated series.

Keywords: Perception; Environmental education; Ecological agriculture; Teaching.

\section{Resumen}

Se entiende que el conocimiento y comprensión de las percepciones de los estudiantes sobre el entorno en el que viven y cómo interactúan con él es fundamental para orientar las prácticas en educación ambiental. El objetivo de esta investigación fue comprender la percepción ambiental de los estudiantes que asisten a escuelas ubicadas en un entorno rural; en cuanto al efecto de los plaguicidas en el medio ambiente y su impacto en la salud humana. El estudio se realizó en dos escuelas primarias del interior de la ciudad de Ijuí, Rio Grande do Sul, de marzo a julio de 2018, con la participación de 20 alumnos por escuela. La investigación fue descriptiva, de carácter cualitativo a partir de la narrativa de los estudiantes, mediante entrevista semiestructurada, teniendo como criterio de inclusión ser hijo de agricultor y / o residente en zona rural. El análisis de contenido se integró en la interpretación y, a través de la minería de textos, se jerarquizó el contenido con la ayuda del software IRaMuTeQ. Los análisis en este estudio fueron: distribución de frecuencia de palabras, frecuencia de palabras según los factores: hijos de agricultores; uso de plaguicidas y género; nube de palabras y análisis de similitud. Se evidenció que la mayoría retuvo para emigrar a la ciudad con el fin de cursar estudios superiores y buscar alternativas de trabajo e ingresos. Se mencionó el uso de plaguicidas en las propiedades y casos de intoxicación. Se encontró que la percepción de aspectos que involucran el entorno difiere debido a la realidad de cada individuo, así como entre las series evaluadas.

Palabras clave: Percepción, Educación ambiental, Agricultura ecológica; Ensenãnza.

\section{Introdução}

A sala de aula é o principal espaço para a realização de atividades de ensino-aprendizagem. Contudo, os espaços não formais de aprendizagem, especialmente a construção de conhecimentos a partir da socialização, do convívio e da experiência, podem contribuir significativamente para a construção de conhecimentos. Caramello (2012) investigou a visão dos problemas socioambientais nos contextos escolares e confirmou que a ausência de uma discussão mais aprofundada por parte dos educandos sobre suas experiências vividas, dificulta o entendimento das noções básicas sobre o meio ambiente. Os alunos de áreas rurais são privilegiados para realizarem estudos ambientais, pois se favorecem com todo o cenário ambiental à sua volta.

Para que se tenha uma maior relevância e significado do aprendizado e para o desenvolvimento da consciência ambiental mais efetiva, a vivência e a realidade dos discentes são muito significativas para a compreensão do meio ambiente. É fundamental pesquisar como os alunos do Ensino Fundamental percebem o meio ambiente e qual a percepção deles sobre florestas, a utilização de agrotóxicos ou a necessidade da preservação dos recursos naturais; pois é a partir da compreensão de como estes sujeitos percebem as questões ambientais, será possível desenvolver estratégias adequadas para a sensibilização, para a mudança de hábitos e de costumes.

O estudo da percepção ambiental é considerado uma ferramenta essencial para a comunidade compreender as ações que podem ser capazes de sensibilizar e desenvolver posturas éticas e responsáveis diante o ambiente. Segundo Brandalise (2009), a percepção ambiental é entendida como uma interpretação que a pessoa faz ao receber uma determinada mensagem e está podendo apresentar desigualdades em relação de quem a recebeu. Se um biólogo e um leitor qualquer abrem o jornal e leem a notícia de que a perda da biodiversidade pode afetar o bem estar das gerações atuais e futuras; a interpretação do biólogo será uma, a de outro leitor não será a mesma.

Já a Educação Ambiental trata-se de uma dimensão educativa crítica, possibilitando a formação de um sujeito-aluno cidadão, comprometido com a sustentabilidade ambiental, em função da apreensão e compreensão do mundo enquanto 
complexo (Figueiredo, 2007, Jacobi, 2003, Loureiro, 2003). Quanto ao termo interpretação da natureza ou interpretação ambiental refere-se a um conjunto de princípios e técnicas que visam estimular as pessoas para o entendimento do ambiente pela experiência prática direta. Seu objetivo básico é revelar os significados, relações ou fenômenos naturais através de experiências práticas e meios interpretativos, ao invés somente da comunicação de dados e fatos (Tilden, 1957). Portanto, esta interpretação visa informar e sensibilizar as pessoas para a compreensão das complexas questões ambientais através de um olhar crítico e reflexivo.

Sobretudo, o ambiente escolar influi na vida dos educandos, no que é aprendido, ouvido, visto e realizado. Se na escola é ensinado a respeitar os recursos naturais, a manejar corretamente o solo, água, plantas e a biodiversidade; maior serão as chances de ter cidadãos responsáveis e comprometidos em não degradar o ambiente que o cerca.

$\mathrm{Na}$ atualidade, os problemas ambientais têm chamado a atenção de diversos pesquisadores; tornando-se relevante construir uma sociedade crítica, ética e engajada a cuidar do ambiente que a cerca. Quanto mais cedo a juventude trabalhar o cuidado com o ambiente, maiores serão as diferenças de pensamentos e atitudes destes no futuro; refletindo assim em maior cuidado com as riquezas naturais.

O uso intensivo de agrotóxicos na região noroeste do Rio Grande do Sul é preocupante, uma vez que a monocultura, principalmente de cereais e grãos, é preponderante, tendo como consequências o aumento das pragas, que não encontram predadores naturais o que exige, em consequência, o aumento no uso de agrotóxicos, implicando no aumento das dosagens para controle.

Com a predominância da monocultura no agronegócio, a biodiversidade tem sido ameaçada, ou seja, existe a constante eminência da perda da diversidade e da variabilidade de espécies. Logo, é urgente a sensibilização na em relação às mudanças decorrentes do descaso humano com o meio ambiente, sob o risco de a biodiversidade ser afetada.

Para compreender as inter-relações entre o homem e ambiente é preciso estudar a percepção ambiental para entender suas expectativas, satisfações, anseios no espaço em que convive (Vasco \& Zakrzevski, 2010). Os estudos possibilitarão construir estratégias que reduzem problemas socioambientais e implementem programas de educação e comunicação, de forma a envolver os atores envolvidos no processo de gestão ambiental.

Diante de questões como esta, é imprescindível as escolas analisarem qual a percepção ambiental dos alunos oriundos de áreas rurais, frente aos diversos elementos que compõem um agroecossistema. Esse cenário real poderá despertar através de discussões uma proposição de uma agricultura ou práticas mais sustentáveis, como a agroecologia. Quanto à situação problema, buscou-se conhecer qual era o conhecimento dos estudantes frente às questões ambientais da atualidade, pois partindo do pressuposto que nem todos os jovens rurais queiram permanecer na propriedade rural, a hipótese é de que podem ser devido ao trabalho do campo ser desvalorizado e árduo. Tais condições estimulam o jovem a buscar por oportunidades na cidade, segundo Carneiro e Castro (2007). O meio urbano passa a ser uma alternativa de inserção no mercado de trabalho e uma vida cheia de novidades. Diante deste cenário torna-se necessário criar formas de atrair o interesse dos jovens em valorizar o estilo de vida rural.

Baseado no exposto é de suma importância às pesquisas que fazem um diagnóstico da percepção que os jovens estudantes têm sobre os diversos aspectos que envolvem as questões ambientais, e desta forma metodologias de educação ambiental podem ser propostas e construídas nas escolas com o intuito de sensibiliza-los quanto a preservação e produção mais sustentável. Deste modo, objetivou-se compreender a percepção ambiental de estudantes que frequentam escolas localizadas em ambiente rural; quanto ao efeito do agrotóxico no ambiente e seu reflexo na saúde humana. 


\section{Metodologia}

\subsection{Delimitação do Estudo}

O estudo foi realizado com alunos do $6^{\circ}$ ao $9^{\circ}$ ano do Ensino Fundamental em dois estabelecimentos de Educação Básica: uma escola municipal e uma escola estadual, ambas localizadas no interior do município de Ijuí - Rio Grande do Sul. A Escola Municipal de Ensino Fundamental Joaquim Nabuco localiza-se na Vila Mauá/SN e atende alunos provenientes deste distrito e arredores. Em sua maioria são filhos de agricultores familiares, incluindo-se os de trabalho temporário e os pequenos proprietários de terra. A Escola Estadual de Ensino Fundamental Santana está localizada na Vila Santana RS -155 Km 06; atende aos alunos deste distrito e alguns oriundos de casas de adoção que não moram com os pais ou foram afastados dos pais por estarem expostos à vulnerabilidade. Os materiais didáticos utilizados nas duas escolas são livros e materiais impressos que os professores distribuem na sala de aula, e as duas possuem sala de leitura, sala de informática e quadra de esportes. A metodologia utilizada são conteúdos trabalhados via escrita no quadro, bem como provas teóricas.

\subsection{Questionário das Entrevistas}

Segundo Fernandes e Pelissari (2003), para o sucesso numa pesquisa que envolve a percepção ambiental é fundamental a qualidade do questionário adotado. Assim, para verificar o que os discentes entendiam sobre sustentabilidade e práticas agroecológicas, foi realizado a entrevista individual semiestruturada. No questionário constou o ano escolar, idade e o nome do participante. Dez das onze perguntas tiveram caráter discursivo (questões abertas). A intencionalidade foi verificar o conhecimento e percepção dos alunos sobre o meio ambiente em que estão inseridos e as práticas sustentáveis de produção de alimentos.

\subsection{Coleta de Dados}

O cuidado na aplicação do questionário foi importante para que não houvesse comunicação entre os alunos, reduzindo, desta forma a possibilidade de interferências externas nas respostas. Não houve nenhum tipo de orientação ou interpretação de questões mesmo quando solicitado pelo discente, sob pena, ainda que intencionalmente, induzisse a resposta do aluno. A duração do questionário foi aproximadamente 60 minutos para os alunos do $6^{\circ}$ ano e uma redução gradativa desse tempo até $09^{\circ}$ ano.

Cabe salientar que durante a aplicação do questionário o professor da turma naquele período não esteve presente, evitando comunicação do docente com o discente; outro fato importante de mencionar é que todas as atividades desta pesquisa se deram na disciplina de Ciências na Escola da rede Municipal e na disciplina de agroecologia na Escola da rede Estadual.

\subsection{Respostas do Questionário}

A tabulação das respostas dos questionários foi realizada separadamente para cada uma das escolas. Na análise destas respostas foi aplicada a análise textual, que permite utilizar métodos quantitativos baseados nos conceitos de estatística (Koche, 2011), como a análise descritiva univariada e bivariada dos dados textuais por meio de Tabelas e Gráficos.

Na E.M.E.F. Joaquim Nabuco o corpus (conjunto de textos) foi composto também por 20 textos, que corresponderam também às respostas das 11 perguntas do questionário aplicado de cada um dos 20 alunos desta escola. Estes textos foram divididos em 83 segmentos de texto, onde foram contabilizadas 2.915 ocorrências (número total de palavras), com 511 palavras distintas e 242 palavras que aparecem uma única vez no corpus.

Na E.E.E.F. Santana o corpus (conjunto de textos) foi composto por 20 textos, que corresponderam às respostas das 11 perguntas do questionário aplicado de cada um dos 20 alunos de tal escola. Estes textos foram divididos em 75 segmentos 
de texto, onde foram contabilizadas 2.530 ocorrências (número total de palavras), com 430 palavras distintas e 202 palavras que aparecem uma única vez no corpus.

$\mathrm{Na}$ análise textual, foi utilizado o software IRaMuTeQ 2009. Esta ferramenta possibilita o processamento da análise estatística textual que apoiaram esta pesquisa. Uma das vantagens deste software é o fato de ser gratuito e de código aberto; e ainda é fundamentado em pacotes da linguagem de programação R. Com o uso do IRaMuTeQ foram realizadas análises de similitude, a nuvem de palavras e tabelas de distribuição e frequência de palavras. Entretanto, é importante ressaltar a arguição de Chartier e Meunier (2001) e reiterada por Lahlou (2012) de que o software não é considerado um método, e os relatórios gerados pelo tal também não são, em si, a análise dos dados.

Nesta pesquisa, utilizou-se a nuvem de palavras para análise textual dos dados. Logo, as palavras são agrupadas e organizadas graficamente de acordo com a sua frequência e a partir de um único arquivo, permite facilmente a identificação, chamado corpus, que engloba os textos originados pelas entrevistas. Portanto, cada entrevista deu origem a um texto, e o conjunto desses textos constituiu o corpus de análise desta pesquisa (Klemann; Reategui; Rapkiewicz, 2011).

Conforme as palavras mais frequentes nos segmentos de texto foram feita a análise lexical, mais simples, mas que graficamente é bastante interessante, pois possibilita identificar rapidamente as palavras-chave de um corpus. Tal análise supera a divisão entre a pesquisa quantitativa e qualitativa, que possibilita empregar cálculos estatísticos sobre dados qualitativos. Ocorre a identificação e quantificação do vocabulário em relação a sua frequência e, em alguns casos, em relação também ao seu posicionamento no texto, ou seja, é submetido a cálculos estatísticos para interpretar posteriormente, considerada uma das diferenças da análise de conteúdo, no qual o pesquisador faz a sua interpretação para sucessivamente sistematizar (Cristofoli, 2012). A (Figura 1) abaixo mostra todos os passos importantes que foram mencionados para a condução desta pesquisa. 
Figura 1 - Apresentação esquemática da forma como foram conduzidas as etapas da pesquisa.

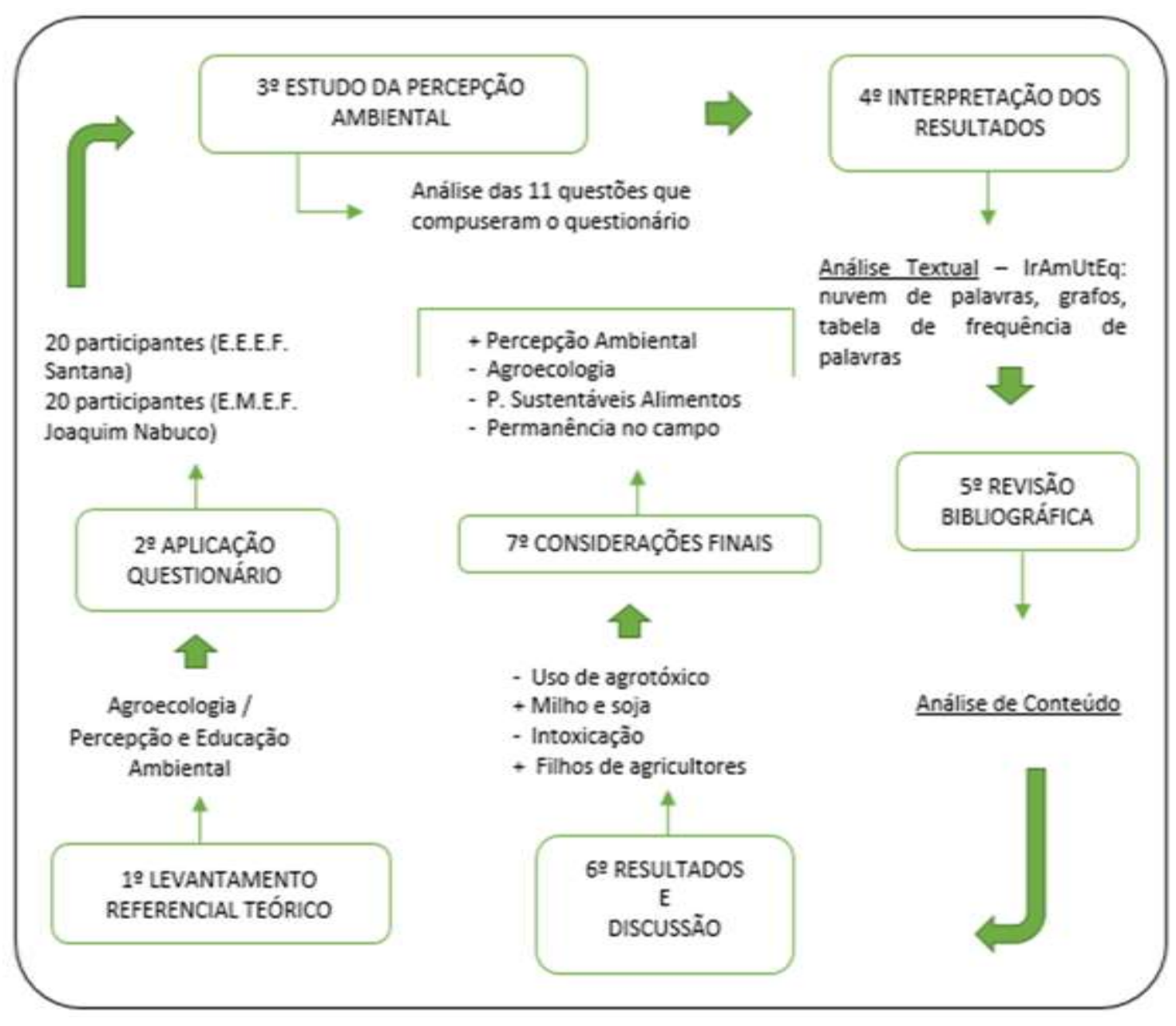

Fonte: Autores.

\section{Resultados e Discussão}

Aqui são apresentados os resultados obtidos na pesquisa da Escola Municipal de Ensino Fundamental Joaquim Nabuco e da Escola Estadual de Ensino Fundamental Santana. Tratará a análise textual conjunta das duas escolas mencionadas, como: Tabela de distribuições de frequência das palavras; Tabela de frequências das palavras segundo os fatores: FILHOS DE AGRICULTORES, GÊNERO, e USO DE AGROTÓXICOS ( $\mathrm{n} \geq 10$ ); tais variáveis foram selecionadas em função da característica da pesquisa, ou seja, no intuito de conhecer quantos eram filhos de agricultores, quais eram do gênero feminino e quais das propriedades usam ou não agrotóxicos. Foi realizada também a Nuvem de palavras e Gráfico da análise de similitude. Abaixo de cada uma dessas análises, ocorrerá também a discussão conjunta de ambas as escolas. Por fim, apresentou - se a análise de conteúdo, ou seja, as referências bibliográficas, as quais serão referenciadas as duas escolas conjuntamente. Importante lembrar que os estabelecimentos não foram comparados estatisticamente.

É imprescindível entender o vínculo que a escola do campo tem com a identidade dos seus alunos. Estudantes do campo são vistos como atores responsáveis pela movimentação e luta pela terra; bem como pela Reforma Agrária. Estes buscam um novo projeto social. Ao analisar as entrevistas observações relevantes puderam ser averiguadas, quanto a permanência no campo, questões de gênero e a sua relação com a agricultura, as quais serão abordados a seguir em subitens: 


\section{a) Permanência no Campo}

Em termos da permanência e continuidade das atividades do campo, a sucessão familiar é imprescindível. Se os filhos dos agricultores decidem permanecer na propriedade, eles mantêm as atividades agrícolas estabelecidas. Tal permanência promove a valorização dos bens e recursos que os pais adquiriram ao longo dos anos; reduzindo a possibilidade de desapropriar as suas terras por um valor ingênuo e irrelevante. Nesta pesquisa, foi observado que muitos desejam migrar para a cidade no intuito de cursar o Ensino Superior e também adquirir emprego:

“[...] eu não pretendo permanecer na colônia porque quero ir estudar na Unijuí pra fazer veterinária [...]” Entrevistado 7 da E.E.E.F. Santana.

"[...] ainda não sei se vou permanecer na propriedade, pois futuramente vou querer trabalhar e na cidade eu acho que consigo mais fácil [...]” - Entrevistado 12 da E.M.E.F. Joaquim Nabuco.

Vários são os motivos que contribuem para a saída do jovem do campo, conforme Brumer (2008) e são fatores como más condições de trabalho associadas às inseguranças de rentabilidade. Partindo desse pressuposto é visto que a maioria dos jovens filhos de agricultores abandonam os serviços familiares e vão para a cidade em busca de melhores condições de renda e uma vida mais atrativa. Segundo o autor, as atividades exercidas no campo não são atraentes quanto aos lucros. Ainda, desentendimentos, processo de sucessão mal estruturado e a escassez de políticas públicas para o fortalecimento da agricultura familiar desestimulam a permanências dos jovens no rural (Oliveira et al., 2021).

Quanto ao fato de quererem ir para a cidade em busca de serviços e fonte de renda, verificou-se que alguns dos participantes se sentiam insatisfeitos com o modo de vida que tinham, mas não quiseram deixar isso tão explícito, sendo que muitos não explicam o porquê de irem em busca de uma fonte de renda no meio urbano. Leccadi (2010) comenta que a família são atores essenciais para o apoio econômico dos jovens. $\mathrm{O}$ apoio dos pais pode ajudar também na proteção contra a incerteza social e emocional, capaz de tranquilizar as aflições sobre a vida futura.

\section{b) Gênero e Agricultura}

Outra questão importante relacionada é a expectativa da permanência da mulher no campo. Sua autoestima deve ser elevada, dar o seu devido reconhecimento:

"[...] sou menina e não quero continuar no campo, o trabalho aqui é duro é mais pra homem, eu como mulher quero uma vida menos dura [...]” - Entrevistado 15 da E.E.E.F. Santana.

“[...] meu irmão fala que não quer sair daqui do interior, mas ele é homem, pra mim já é difícil porque não quero ficar trabalhando na lavoura com terra e no sol [...]" - Entrevistado 9 da E.M.E.F. Joaquim Nabuco.

Segundo Dalcin e Troian (2009) ressaltam que já foram realizadas pesquisas tratando a questão da permanência no meio rural de mulheres e um dos motivos que levam essa saída do campo para cidade está a desvalorização feminina refletida na autoestima da jovem, além do ato da sucessão da área rural destinar-se em grande parte ao filho homem.

\subsection{Análises Textuais}

$\mathrm{Na}$ análise textual da E.E.E.F. Santana, foram consideradas apenas as palavras classificadas como substantivos e adjetivos mais relevantes, totalizando assim 600 ocorrências (23,72\% do total), com 110 palavras distintas (25,58\% do total) e 34 palavras (16,83\% do total) que aparecem uma única vez no corpus. Na Tabela 1, são apresentadas as distribuições de frequências das palavras com $\mathrm{n} \geq 10$. 
$\mathrm{Na}$ análise textual da E.E.F. Joaquim Nabuco, foram consideradas também apenas as palavras classificadas como substantivos e adjetivos mais relevantes, totalizando assim 827 ocorrências (28,37\% do total), com 193 palavras distintas (37,77\% do total) e 81 palavras (33,47\% do total) que aparecem uma única vez no corpus. Na Tabela 2, são apresentadas as distribuições de frequências das palavras com $n \geq 10$.

Tabela 1 - Distribuição de frequência das palavras (somente com substantivos e adjetivos) E.E.E.F. Santana.

\begin{tabular}{|c|c|c|}
\hline Palavras & $\begin{array}{l}\text { Frequência } \\
\text { (n) }\end{array}$ & $\begin{array}{c}\text { Frequência Percentual } \\
\qquad(\%)\end{array}$ \\
\hline Agrotóxico & 41 & 6,83 \\
\hline Água & 33 & 5,50 \\
\hline Meio ambiente & 25 & 4,17 \\
\hline Pais & 23 & 3,83 \\
\hline Sustentabilidade & 21 & 3,50 \\
\hline Campo & 21 & 3,50 \\
\hline Práticas sustentáveis de alimentos & 20 & 3,33 \\
\hline Filho de agricultores & 20 & 3,33 \\
\hline Meio rural & 19 & 3,17 \\
\hline Agricultura no futuro & 18 & 3,00 \\
\hline Propriedade & 17 & 2,83 \\
\hline Agroecologia & 17 & 2,83 \\
\hline Veneno & 16 & 2,67 \\
\hline Importante & 16 & 2,67 \\
\hline Cidade & 16 & 2,67 \\
\hline Doença & 14 & 2,33 \\
\hline Solo & 13 & 2,17 \\
\hline Cuidado & 13 & 2,17 \\
\hline Alimento & 12 & 2,00 \\
\hline Poço & 11 & 1,83 \\
\hline Soja & 10 & 1,67 \\
\hline $\mathrm{n}<10$ & 204 & 34,00 \\
\hline Total & 600 & 100,00 \\
\hline
\end{tabular}

Distribuições de frequências das palavras com $n \geq 10$. Fonte: Autores. 
Tabela 2 - Distribuição de frequência das palavras (somente com substantivos e adjetivos) E.M.E.F. Joaquim Nabuco.

\begin{tabular}{|c|c|c|}
\hline Palavras & $\begin{array}{l}\text { Frequência } \\
\text { (n) }\end{array}$ & $\begin{array}{c}\text { Frequência Percentual } \\
\qquad(\%)\end{array}$ \\
\hline Agrotóxico & 46 & 10,48 \\
\hline Pais & 38 & 8,66 \\
\hline Água & 35 & 7,97 \\
\hline Campo & 34 & 7,74 \\
\hline Meio rural & 23 & 5,24 \\
\hline Meio ambiente & 23 & 5,24 \\
\hline Práticas sustentáveis de alimentos & 20 & 4,56 \\
\hline Propriedade & 20 & 4,56 \\
\hline Agroecologia & 20 & 4,56 \\
\hline Sustentabilidade & 19 & 4,33 \\
\hline Importante & 17 & 3,87 \\
\hline Filho de agricultores & 17 & 3,87 \\
\hline Agricultura no futuro & 17 & 3,87 \\
\hline \multirow[t]{2}{*}{ Cidade } & 16 & 3,64 \\
\hline & Frequência & Frequência Percentual \\
\hline Palavras & (n) & $(\%)$ \\
\hline Veneno & 15 & 3,42 \\
\hline Milho & 14 & 3,19 \\
\hline Soja & 12 & 2,73 \\
\hline Poço & 11 & 2,51 \\
\hline Máquina & 11 & 2,51 \\
\hline Alimento & 11 & 2,51 \\
\hline Doença & 10 & 2,28 \\
\hline Cuidado & 10 & 2,28 \\
\hline Total & 439 & 100,00 \\
\hline
\end{tabular}

Distribuições de frequências das palavras com $n \geq 10$. Fonte: Autores.

Importante salientar que foi considerado palavras que apresentaram no mínimo frequência maior ou igual a dez, ou seja, que apareceram no mínimo dez vezes. O procedimento vem apoiar mais uma vez o que os outros procedimentos trouxeram como resultados. Na análise da E.E.E.F. Santana do total de 600 palavras, as 5 palavras de mais destaque foram agrotóxico $(n=41 ; 6,83 \%)$, água $(n=33 ; 5,50 \%)$, meio ambiente $(n=25 ; 4,17 \%)$, pais $(n=23 ; 3,83 \%)$ e sustentabilidade $(n=$ 21; 3,50\%). Já na E.M.E.F. Joaquim Nabuco não apresentou diferença significativa na riqueza de palavras, a qual foi de 827 palavras, os quais de maior destaque apresentaram semelhanças a análise da Escola Estadual, uma vez que, a palavra agrotóxico também se destacou com $(n=46 ; 10,48 \%)$, pais $(n=38 ; 8,66 \%)$, água $(35 ; 7,97 \%)$ e campo $(n=34 ; 7,74 \%)$.

A maior frequência da palavra agrotóxico vem ao encontro do uso intensivo de agrotóxicos na região, uma vez que a monocultura, principalmente de cereais e grãos é preponderante. Uma das consequências da monocultura é o aumento das pragas, que não encontram predadores naturais e exigem que sejam utilizados ainda mais agrotóxicos. Grandes culturas como o milho, soja, trigo e o arroz contribuem para maiores aplicações de agrotóxicos na lavoura. Segundo Ibama (2016) o consumo 
de agrotóxicos no Rio Grande do Sul atingiu o nível de 54 mil toneladas de princípios ativos, uma média de 6,4 kg de princípio ativo de agrotóxicos por hectare.

Quanto a segunda maior frequência a palavra água tem seu sentido quando o uso do agrotóxico comprometem sua qualidade. O cultivo de arroz, por exemplo, presentes em grandes áreas do Rio Grande do Sul geram conflitos pontuais com o abastecimento hídrico, em função do uso de agrotóxicos (Zini, 2016). Carneiro et al. (2015), reforça que a problemática dos agrotóxicos em água para consumo humano no Brasil é tema pouco pesquisado e sobre o qual se dispõe de escasso número de fontes oficiais de informações acessíveis para consulta. Um ponto relevante é o processo de escoamento dos produtos químicos que escoam até os recursos hídricos. Para a ocorrência deste processo é preciso umidade e porosidade do solo, podendo acarretar na contaminação do lençol freático. Outro meio de contaminação da água é o escoamento superficial, contaminando a sua parte superficial resultando na toxicidade de diversos organismos aquáticos e espécies pelo nível de agrotóxico (Rebelo \& Caldas, 2014). Além disto, o principal canal de transporte dos agrotóxicos utilizados no campo até os mananciais é a chuva (Silva et al., 2016).

No intuito de conhecer o perfil dos discentes, foi realizada também para cada escola a análise fatorial confirmatória (AFC), tendo como fatores: filhos de agricultores (Tabelas 3 e 4) e uso de agrotóxicos (Tabelas 5 e 6 ). 
Tabela 3 - Frequência das palavras segundo o fator FILHO DE AGRICULTORES ( $\mathrm{n} \geq 10$ ) da Escola Estadual de Ensino Fundamental Santana.

\begin{tabular}{|c|c|c|c|}
\hline \multirow[b]{2}{*}{ Palavras } & \multicolumn{2}{|c|}{ Filhos de agricultores } & \multirow[b]{2}{*}{ Total } \\
\hline & $\begin{array}{c}\text { SIM } \\
(\mathbf{n}=\mathbf{1 7})\end{array}$ & $\begin{array}{l}\text { NÃO } \\
(\mathbf{n}=\mathbf{3})\end{array}$ & \\
\hline Agrotóxico & 33 & 8 & 41 \\
\hline Água & 27 & 6 & 33 \\
\hline Meio ambiente & 21 & 4 & 25 \\
\hline Sustentabilidade & 18 & 3 & 21 \\
\hline Pais & 18 & 5 & 23 \\
\hline Filho de agricultores & 17 & 3 & 20 \\
\hline Meio rural & 17 & 2 & 19 \\
\hline Práticas sustentáveis de alimentos & 17 & 3 & 20 \\
\hline Agricultura no futuro & 16 & 2 & 18 \\
\hline Importante & 15 & 1 & 16 \\
\hline Veneno & 15 & 1 & 16 \\
\hline Campo & 15 & 6 & 21 \\
\hline Agroecologia & 15 & 2 & 17 \\
\hline Propriedade & 14 & 3 & 17 \\
\hline Doença & 12 & 2 & 14 \\
\hline Solo & 12 & 1 & 13 \\
\hline Cidade & 12 & 4 & 16 \\
\hline Alimento & 11 & 1 & 12 \\
\hline Cuidado & 11 & 2 & 13 \\
\hline Poço & 10 & 1 & 11 \\
\hline Soja & 10 & 0 & 10 \\
\hline
\end{tabular}

Fonte: Elaborado pelos autores com base no software IRaMuTeQ - (2018). 
Tabela 4 - Frequência das palavras segundo o fator FILHO DE AGRICULTORES ( $\mathrm{n} \geq 10$ ) da Escola Municipal Joaquim Nabuco.

\begin{tabular}{|c|c|c|c|}
\hline \multirow{4}{*}{ Palavras } & \multicolumn{2}{|c|}{ Filhos de agricultores } & \multirow{4}{*}{ Total } \\
\hline & \multicolumn{2}{|c|}{$\mathrm{n}(\%)$} & \\
\hline & SIM & NÃO & \\
\hline & $(\mathrm{n}=16)$ & $(n=4)$ & \\
\hline Agrotóxico & 37 & 9 & 46 \\
\hline Pais & 29 & 9 & 38 \\
\hline Campo & 29 & 10 & 35 \\
\hline Água & 25 & 5 & 34 \\
\hline Meio ambiente & 18 & 5 & 23 \\
\hline Meio rural & 17 & 6 & 23 \\
\hline Práticas sustentáveis de alimentos & 16 & 4 & 20 \\
\hline Agroecologia & 16 & 4 & 20 \\
\hline Sustentabilidade & 15 & 4 & 19 \\
\hline Propriedade & 15 & 5 & 20 \\
\hline Milho & 13 & 1 & 14 \\
\hline Importante & 13 & 4 & 17 \\
\hline Filho de agricultores & 13 & 4 & 17 \\
\hline Cidade & 13 & 3 & 16 \\
\hline Agricultura no futuro & 13 & 4 & 17 \\
\hline Veneno & 12 & 3 & 15 \\
\hline Alimento & 11 & 0 & 11 \\
\hline Soja & 10 & 2 & 12 \\
\hline Poço & 10 & 1 & 11 \\
\hline
\end{tabular}

Fonte: Elaborado pelos autores com base no software IRaMuTeQ - (2018).

Quanto ao fator filho de agricultores, observou-se na análise da (E.E.E.F. Santana) que as palavras mais evocadas, no grupo SIM foram: agrotóxico $(n=33)$, água $(n=27)$, meio ambiente $(n=21)$, sustentabilidade e pais $(n=18)$. Enquanto que, no grupo NÃO foram: agrotóxico $(n=8)$, água e campo $(n=6)$, pais $(n=5)$, meio ambiente e cidade $(n=4)$. Sobre o referente fator, na E.M.E.F. Joaquim Nabuco as palavras mais evocadas no grupo SIM foram: agrotóxico $(n=37)$, pais e campo $(n=29)$ e água $(\mathrm{n}=25)$. Já no grupo NÃO foram: agrotóxico e pais $(\mathrm{n}=9)$, campo $(\mathrm{n}=10)$ e água $(\mathrm{n}=5)$.

É possível notar que dezessete dos participantes da E.E.E.F. Santana são filhos de agricultores e apenas três não são, mas que moram no meio rural e que tem algum contato com a agricultura. Quanto as palavras de maiores frequências para os que são filhos de agricultores e para os que não são, apresentaram poucas diferenças; sendo que as palavras mais evocadas nos dois grupos foram: agrotóxico, água, meio ambiente e pais. Os grupos apenas se diferiram com a palavra sustentabilidade no grupo sim e a palavra cidade no grupo não. Na E.M.E.F. Joaquim Nabuco dentre os participantes dezesseis são filhos de agricultores e apenas quatro não são, mas também residem no meio rural.

A frequência maior da palavra agrotóxico no grupo SIM do que no grupo NÃO, justifica-se pelo fato de que se produzem alimentos, mais contato terá com tal palavra, seja no ato de usar ou apenas ter conhecimento do que ela representa. 
Estudo realizado por Espíndola (2011) na Escola de Engenharia de São Carlos (E.E.S.C.) da Universidade de São Paulo (USP) mostrou que a maior parte dos agricultores familiares que faz uso de agrotóxicos em suas plantações tem consciência dos seus malefícios causados pelo o seu uso, mas por falta de alterativas, conhecimento técnico, orientação técnica, fiscalização dos órgãos, acabam utilizando. Tal confirmação pode ser notada também nesta pesquisa, cujo houve menção do uso de agrotóxico, como também dos seus males para com a saúde dos agricultores.

Quanto mais se exerce atividades no ramo agrícola, maior será a noção sobre a conservação dos recursos naturais, dos efeitos dos químicos, da importância do manejo correto do solo, ou seja, a percepção de ambiente de um filho dos quais os pais vivem das atividades do campo se difere da percepção de um outro que não seja filho de agricultores, que não tenha um contato diário com a agricultura. Outro fator que pode intervir no manejo ecológico das propriedades é o o nível de escolaridade, pois não tem contribuído nas buscas de técnicas alternativas para a não utilização de agrotóxicos. Estudo realizado por Lucena (2010) no município de Jurucutu - RN verificou que a maior parte dos agricultores familiares não chegaram a cursar o $2^{\circ}$ grau completo. Entretanto, pessoas com maior grau de escolaridade também poluem e não preservam o meio ambiente. Em relação com o presente estudo, observou-se também que muitos dos pais cursaram apenas a educação básica; exercendo atividades como carpinteiro, pedreiro, trabalhador rural, caseiro, entre outras.

Apesar das frequências das palavras entre os gêneros não apresentarem diferenças significativas, sabe-se que na realidade rural a igualdade de gênero vem sendo cada vez mais discutido. Quando se fala no papel e importância da mulher no espaço rural desde o cuidado com os filhos e o lar, ela desempenha também importante função na produção familiar e sustentabilidade. Contudo, é preciso viabilizar a inserção da mulher nas políticas rurais para que elas tenham autonomia. A igualdade de gênero na agricultura precisa ser fortalecida, pois o cotidiano das tarefas de plantio, colheita, manejo da terra não estão presentes apenas para o gênero masculino, mas a feminilidade também soma forças na condução da propriedade. Porém, as mulheres permanecem na margem das decisões do homem, tendo-o como um chefe de família. Tal confirmação pode ser notada em falas dos entrevistados:

"[...] quem cuida da horta é minha mãe ela capina com enxada, aduba a terra com esterco e faz o preparo das mudas...meu pai as vezes ajuda, mas é ele que escolhe o que é plantado" - Entrevistado 11 da E.E.E.F. Santana.

"[...] não sei se vamos permanecer na colônia, meu pai é quem decide se vamos ficar ou não” - Entrevistado 3 -da E.M.E.F. Joaquim Nabuco.

Brasil (2013) a política pública relata sobre a necessidade de elaborar medidas para examinar políticas de forma a estabelecer planos que sirvam para crescer a proporção de mulheres que possuem autonomia, ou seja, que tomem a sua própria decisão, no meio rural. $\mathrm{O}$ autor ainda destaca que as políticas de incentivo a mulher do campo venham de encontro com a agricultura familiar e desenvolvimento sustentável.

Para isso, tais mudanças não exigem só dos homens; mulheres podem se unirem para buscar, planejar, e administrar às suas unidades rurais. No entanto, sabe-se que a realidade não é assim que funciona, pois no campo agrícola as atividades femininas e masculinas são diferenciadas; os homens se inserem na esfera produtiva (como por exemplo o que cultivar e o planejamento da área), ou seja, a eles são vinculadas as ações de maior valor social; enquanto as mulheres são inseridas nas atividades de cunho reprodutivo, o que corresponde os princípios básicos da divisão de gênero do trabalho: a separação e também da hierarquização das atividades de homens e mulheres (Hirata \& Kergoat, 2010).

Neste âmbito de ampliar a autonomia pessoal e econômica das mulheres, esta teve êxito segundo Freire (2010, p. 22) por meio do Programa Nacional e Agricultura Familiar (Pronaf), que auxiliou no "crescimento significativo do número de contratos de crédito para as mulheres, tanto pelo Pronaf, como por suas modalidades gerais", posicionando estas no setor 
decisivo tanto na aplicação quanto nos resultados econômicos agrícolas, viabilizando seu reconhecimento como trabalhador rural, e ainda despertando sua competência nas atividades.

Freire sobressai que ainda na tentativa de contribuir para a autonomia feminina rural principalmente nas pequenas propriedades é a criação do Programa de Organização Produtiva das Mulheres Rurais que segundo o autor "promoveria o fortalecimento das organizações de trabalhadoras e ainda incentivaria a troca de conhecimentos e experiências", ancorado a cursos de capacitação, alertando para o curso sobre políticas públicas; a qual daria ainda maior possibilidade de instrumentalizar as mulheres no envolvimento da produção e comercialização de seus alimentos.

Quando a mulher tem a percepção subjetiva do seu reconhecimento, torna-se possível o crescimento da sua participação em espaços produtivos da agricultura. Se elas se enxergam como conhecedoras e manipuladores de todo o processo produtivo desenvolvido em suas propriedades rurais familiares; conseguirão chegar a um patamar de igualdade ao gênero oposto (Wommer \& Cassol, 2014).

O plano nacional para as mulheres estabelece ações que venham fortalecer e implementar as ações que estimulem e dão oportunidade da valorização e permanência da mulher no campo; e ainda o desenvolvimento de políticas direcionadas para a sustentabilidade (Brasil, 2013).

O plano de Políticas Públicas para mulheres destaca que:

O que se defende como desenvolvimento sustentável supõe mudanças fundamentais nos padrões de desenvolvimento ainda vigentes no país, estabelecendo como um de seus princípios norteadores a promoção da igualdade nas suas diferentes dimensões. A igualdade de gênero, portanto, constitui uma exigência básica para a promoção do desenvolvimento sustentável e solidário. (Brasil, 2013, p. 60).

Com base nisso, a mulher é ainda subjugada em muitos aspectos, mas apesar disso tem seu papel fundamental, pois é ela quem educa os filhos, não se limitando a isto, pois sua capacidade vai além com a alimentação, saúde humana e organização do lar. Isso implica refletir sobre a igualdade de gêneros que permite um consenso na produção agrícola e também administração rural.

Tornou-se interessante neste estudo realizar também a Tabela de frequência das palavras com o fator uso de agrotóxico (Tabelas 7 e 8). A mesma possibilitou conhecer o número de propriedades que fazem o uso de agroquímicos. 
Research, Society and Development, v. 10, n. 6, e27610615875, 2021

(CC BY 4.0) | ISSN 2525-3409 | DOI: http://dx.doi.org/10.33448/rsd-v10i6.15875

Tabela 5 - Frequências das palavras segundo o fator USO DE AGROTÓXICOS ( $\mathrm{n} \geq 10$ ) da Escola Estadual de Ensino Fundamental Santana.

\begin{tabular}{ccccc}
\hline \multirow{2}{*}{ Palavras } & \multicolumn{3}{c}{ Uso de agrotóxicos } & \multirow{2}{*}{ Total } \\
\cline { 2 - 4 } & $\begin{array}{c}\text { SIM } \\
(\mathbf{n}=\mathbf{4})\end{array}$ & $\begin{array}{c}\mathbf{N} \mathbf{A} \mathbf{O} \\
(\mathbf{n}=\mathbf{7})\end{array}$ & $\begin{array}{c}\text { IN/NR } \\
(\mathbf{n}=\mathbf{9})\end{array}$ & \\
\hline Agrotóxico & 9 & 14 & 18 & 41 \\
Água & 8 & 11 & 14 & 33 \\
Solo & 5 & 3 & 5 & 13 \\
Meio ambiente & 5 & 7 & 13 & 25 \\
Filho de agricultores & 4 & 7 & 9 & 20 \\
Importante & 4 & 6 & 6 & 16 \\
Doença & 4 & 5 & 5 & 14 \\
Meio rural & 4 & 8 & 7 & 19 \\
Práticas sustentáveis de alimentos & 4 & 7 & 9 & 20 \\
Sustentabilidade & 4 & 8 & 9 & 21 \\
Campo & 4 & 4 & 13 & 21 \\
Agroecologia & 4 & 7 & 6 & 17 \\
Cuidado & 4 & 1 & 8 & 13 \\
Pais & 4 & 7 & 12 & 23 \\
Soja & 4 & 1 & 5 & 10 \\
Agricultura no futuro & 4 & 7 & 7 & 18 \\
Propriedade & 4 & 7 & 6 & 17 \\
Alimento & 3 & 3 & 6 & 16 \\
Veneno & 2 & 6 & 8 & 16 \\
Cidade & 2 & 7 & 7 & 16 \\
Poço & 2 & 5 & 4 & \\
& & & 9 & 16 \\
\hline
\end{tabular}

Fonte: Elaborado pelos autores com base no software IRaMuTeQ - (2018). 


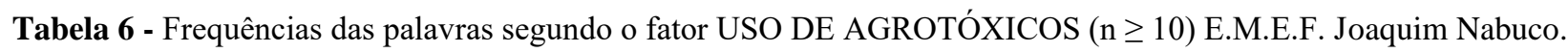

\begin{tabular}{|c|c|c|c|c|}
\hline \multirow[b]{2}{*}{ Palavras } & \multicolumn{3}{|c|}{ Uso de agrotóxicos } & \multirow[b]{2}{*}{ Total } \\
\hline & $\begin{array}{c}\text { SIM } \\
(n=8)\end{array}$ & $\begin{array}{c}\text { NÃO } \\
(n=10)\end{array}$ & $\begin{array}{l}\text { IN/NR } \\
(n=2)\end{array}$ & \\
\hline Agrotóxico & 19 & 24 & 3 & 46 \\
\hline Campo & 16 & 14 & 4 & 34 \\
\hline Água & 15 & 15 & 5 & 35 \\
\hline Pais & 15 & 19 & 4 & 38 \\
\hline Meio rural & 10 & 12 & 1 & 23 \\
\hline Meio ambiente & 9 & 12 & 2 & 23 \\
\hline Propriedade & 9 & 9 & 2 & 20 \\
\hline Agroecologia & 8 & 10 & 2 & 20 \\
\hline Importante & 8 & 8 & 1 & 17 \\
\hline Milho & 8 & 5 & 1 & 14 \\
\hline Agricultura no futuro & 8 & 7 & 2 & 17 \\
\hline Práticas sustentáveis de alimentos & 8 & 10 & 2 & 20 \\
\hline
\end{tabular}

\begin{tabular}{|c|c|c|c|c|}
\hline \multirow[b]{2}{*}{ Palavras } & \multicolumn{3}{|c|}{ Uso de agrotóxicos } & \multirow[b]{2}{*}{ Total } \\
\hline & $\begin{array}{c}\text { SIM } \\
(n=8)\end{array}$ & $\begin{array}{c}\text { NÃO } \\
(n=10)\end{array}$ & $\begin{array}{l}\text { IN/NR } \\
(n=2)\end{array}$ & \\
\hline Sustentabilidade & 8 & 9 & 2 & 19 \\
\hline Máquina & 7 & 2 & 2 & 11 \\
\hline Filho de agricultores & 7 & 8 & 2 & 17 \\
\hline Soja & 7 & 5 & 0 & 12 \\
\hline Cuidado & 6 & 2 & 2 & 10 \\
\hline Doença & 5 & 5 & 0 & 10 \\
\hline Cidade & 5 & 10 & 1 & 16 \\
\hline Alimento & 5 & 6 & 0 & 11 \\
\hline Veneno & 5 & 6 & 4 & 15 \\
\hline Poço & 3 & 6 & 2 & 11 \\
\hline
\end{tabular}

Fonte: Elaborado pelos autores com base no software IRaMuTeQ - (2018).

Quanto à variável Uso de Agrotóxicos, a E.M.E.F. Joaquim Nabuco teve como palavras mais evocadas, no grupo SIM: agrotóxico $(n=19)$, campo $(n=16)$, água e pais $(n=15)$, e meio rural $(n=10)$; no grupo NÃO foram: agrotóxico $(n=$ 24), pais $(n=19)$, água $(n=15)$, campo $(n=14)$, e meio rural e meio ambiente $(n=12)$. Enquanto que, no grupo INDECISO/ NÃO RESPONDEU foram: água $(n=5)$, veneno, campo e pais $(n=4)$, e agrotóxico $(n=3)$.

Referente a variável Uso de Agrotóxicos, na E.E.E.F.Santana as palavras mais evocadas, no grupo SIM foram: agrotóxico $(\mathrm{n}=9)$, água $(\mathrm{n}=8)$, meio ambiente e solo $(\mathrm{n}=5)$; no grupo NÃO foram: agrotóxico $(\mathrm{n}=14)$, água $(\mathrm{n}=11)$, sustentabilidade e meio rural $(n=8)$. Enquanto que, no grupo INDECISO/ NÃO RESPONDEU foram: agrotóxico ( $\mathrm{n}=18$ ), água $(\mathrm{n}=14)$, meio ambiente e campo $(\mathrm{n}=13)$ e pais $(\mathrm{n}=12)$.

Nos dias atuais as rotinas dos agricultores são cheias de tarefas seja no cuidado com os animais, a condução da lavoura, o manejo e cuidado com o solo; no entanto a agricultura convencional vem os colocando a mercê dos agrotóxicos, 
principalmente no que diz respeito a monocultura (Lellis, 2016). Entre os participantes da pesquisa verificou-se que há predominância do contato com culturas como o milho e principalmente a soja, o que consequentemente acarreta ao uso dos agrotóxicos:

"[...] meu pai planta soja também, faz o preparo da terra com maquinário e a colheita também é com uso de máquinas e para as pragas aplicamos veneno" - Entrevistado 17 da E.M.E.F. Joaquim Nabuco.

"[...] além da horta e dos pomares temos soja e um pouco de milho para alimentar os animais, no milho o manejo conseguimos alguma coisa manual" - Entrevistado 6 da E.E.E.F. Santana.

“[...] cultivamos couve, beterraba, cenoura, alface, mas o que mais temos é soja e um pouco de trigo [...]" Entrevistado 20 da E.M.E.F. Joaquim Nabuco.

Para produzir alimentos sem agrotóxicos, uma alternativa é a agricultura de base ecológica, cujos benefícios refletem em melhorias a saúde humana e ao mesmo tempo ao meio ambiente; preservando os ciclos biológicos do solo junto a biodiversidade. Em uma agricultura ecológica não se faz uso de agroquímicos, e ocorrem mudanças no manejo de forma a garantir uma adequada nutrição e proteção das plantas, por meio de fontes orgânicas de nutrientes e um manejo integrado de pragas (Altieri, 2012).

Quanto ao crescimento do uso de máquinas no campo, é entendido que a utilização de equipamentos agrícolas facilita o trabalho dos agricultores. Em contrapartida os mesmos movimentam-se menos, gastam menos energia, beneficiando a ocasião de ganho ponderal, segundo Cruz (2014).

Nesse aspecto, percebe-se que mesmo se tratando de agricultores familiares, o uso do maquinário agrícola é presente, bem como a monocultura da cultura da soja (Glycine max) e do milho (Zea mays). Teixeira (2005) explica que os trabalhadores rurais atualmente investem na produção de alimentos de modo mais mecanizado, desde a utilização de equipamentos, máquinas e insumos modernos de modo a facilitarem sua vida no campo. O autor ainda assegura que em contrapartida no controle de pragas e plantações, o uso de recursos químicos é buscado pelos agricultores. Mudanças na produção de alimentos tem mudado o perfil do agricultor, quando se torna modernizado, refletindo também na mudança de seu estilo de vida (Brandemburg, 2010).

Consequentemente, a expansão do agronegócio vem contribuindo para o extremo uso de agrotóxicos. Produtores, na ânsia do aumento de produtividade deixam de lado a preocupação com sua saúde e a da população. Londres (2011) vem confirmar tal afirmação quando ressalta que o uso exacerbado de agrotóxicos se dá principalmente pelo crescimento do agronegócio, o autor menciona que além do fato de causar intoxicação da população, tem sido responsável pela contaminação dos alimentos, as águas e o ar.

Contudo, as culturas como a soja, o milho, o arroz e o trigo são responsáveis por 10\% das atividades agropecuárias exercidas no Rio Grande do Sul; juntas são as principais culturas agrícolas em grande área cultivada contribuindo com 49\% do valor bruto da produção agropecuária do Estado, do total de 48,5 bilhões de reais em 2014 (Feix \& Leusin Júnior, 2015).

Entre os entrevistados poucos foram os casos mencionados de ocorrência de sinais e sintomas de intoxicação relacionados ao uso do agrotóxico, respectivamente foram mencionados apenas dois casos:

"[...] usamos agrotóxico meu pai usa na soja uma vez quando ele foi aplicar sentiu dor de cabeça e tontura" - Entrevistado 14 da E.E.E.F. Santana.

“[...] não usamos agrotóxicos, mas na casa da minha avó usam e um dia ela comeu um figo e vomitou muito tivemos que levar ela para o hospital porque ela tinha sido intoxicada” - Entrevistado 4 da E.E.E.F. Santana. 
Segundo a Anvisa (2011) ao serem consumidos agrotóxicos através de alimentos ou água por repetidas e pequenas quantidades em um tempo prolongado, tal situação pode contribuir para intoxicações crônicas. Dentre os riscos à saúde podem ser citados problemas respiratórios graves, alteração do funcionamento do fígado e dos rins, anormalidade da produção de hormônios da tireoide, dos ovários e da próstata, incapacidade de gerar filhos, malformação e problemas no desenvolvimento intelectual e físico das crianças, câncer, etc.

Como já ressaltado, foi realizada também a análise de nuvem de palavras para analisar os dados. Este método agrupa as palavras e as organiza graficamente em função da sua frequência, as palavras: agrotóxico e água, foram as que tiveram maiores frequência na E.E.E.F. Santana; enquanto que as palavras: agrotóxico, campo, pai e água tiveram maiores frequência na E.M.E.F. Joaquim Nabuco (Figura 1).

Nota-se na Figura 1 que as palavras são posicionadas aleatoriamente de tal forma que as mais frequentes aparecem maiores que as outras, demonstrando, assim, seu destaque no corpus de análise da pesquisa. Para fins deste estudo, após as etapas de processamento, foram interpretados os sentidos das palavras nos discursos dos alunos, dessa forma na (E.E.E.F. Santana) a palavra "agrotóxico" teve o sentido de algo prejudicial, uma vez que, tal palavra apareceu associado com o vocábulo "veneno".

Figura 1 - Nuvem de palavras E.E.E.F. Santana (A) e E.M.E.F. Joaquim Nabuco (B).

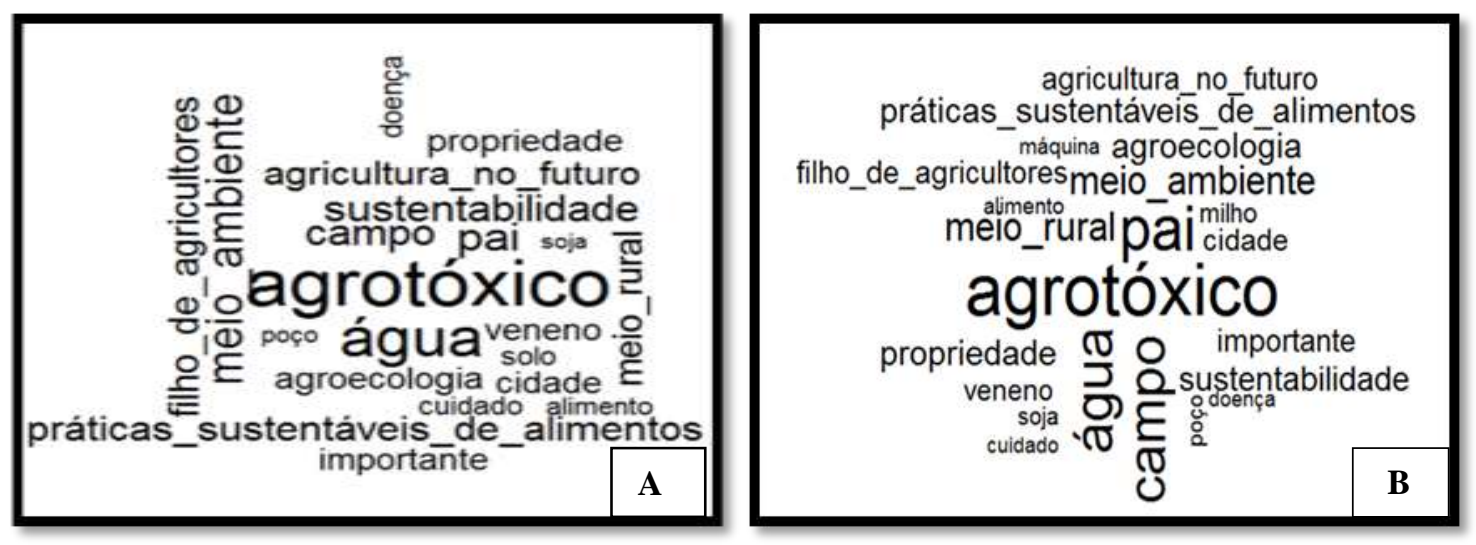

Fonte: Elaborado pelos autores com base no software IRaMuTeQ - (2018).

Diante da palavra de maior destaque, se deduz que muitos dos agricultores fazem o uso de agrotóxicos por acreditarem que o produto garantirá aumento da produção bem como proteção de seus cultivos contra o ataque de pragas e doenças. Segundo Scorza Junior et al. (2010), a maior vantagem decorrente ao uso dos agroquímicos é o aumento da produtividade e rentabilidade das atividades agrícolas; isso é o que conduz muitos agricultores visualizarem as práticas da agricultura convencional como a única opção viável para o desenvolvimento da sua lavoura, deixando de lado as técnicas ecológicas ou alternativas de produção (Veiga, 2007).

A menção da palavra "água" se deve ao relato da procedência do recurso hídrico da sua propriedade; bem como se tal recurso natural era protegido. Outra importância deste recurso se dá na manutenção e abastecimento das atividades agrícolas, pecuárias e de sobrevivência. No entanto, este é também um dos recursos que sofre contaminação devido aos efeitos da agricultura convencional. Entretanto, Moran (2011) fortalece que para trilhar o caminho rumo ao desenvolvimento sustentável, é imprescindível ir além do discurso da sustentabilidade, pois não necessariamente todas apresentam definições claras ou medidas efetivas de melhorias a serem introduzidas. Assim, os processos para avaliação da sustentabilidade precisam ser 
monitorados, só assim será possível viabilizar as mudanças necessárias ao desenvolvimento sustentável, principalmente quando se trata do meio rural (Gomes \& Malheiros, 2012).

Um outro destaque apresentado na nuvem de palavras da E.M.E.F. Joaquim Nabuco é o termo "campo". É interessante analisar como os educandos visualizam seu espaço natural, ou seja, quais os recursos presentes e se os mesmos são preservados. Lovatto et al. (2008) estudaram a percepção de agricultores sobre a importância das florestas para regular o clima, proteger as nascentes, e na preservação da fauna, porém, verificaram que os agricultores têm dificuldades de refletir e sobre estes aspectos; possivelmente seja pela falta de informações, e que ainda parte destes não saiba o papel fundamental das florestas.

Em seguida, as Figuras 2 e 3 representam a análise de similitude da E.E.E.F. Santana (Figura 2) e da E.M.E.F. Joaquim Nabuco (Figura 3) que contribuiu para mais análises importantes.

Figura 2 - Gráfico da análise de similitude da E.E.E.F. Santana.

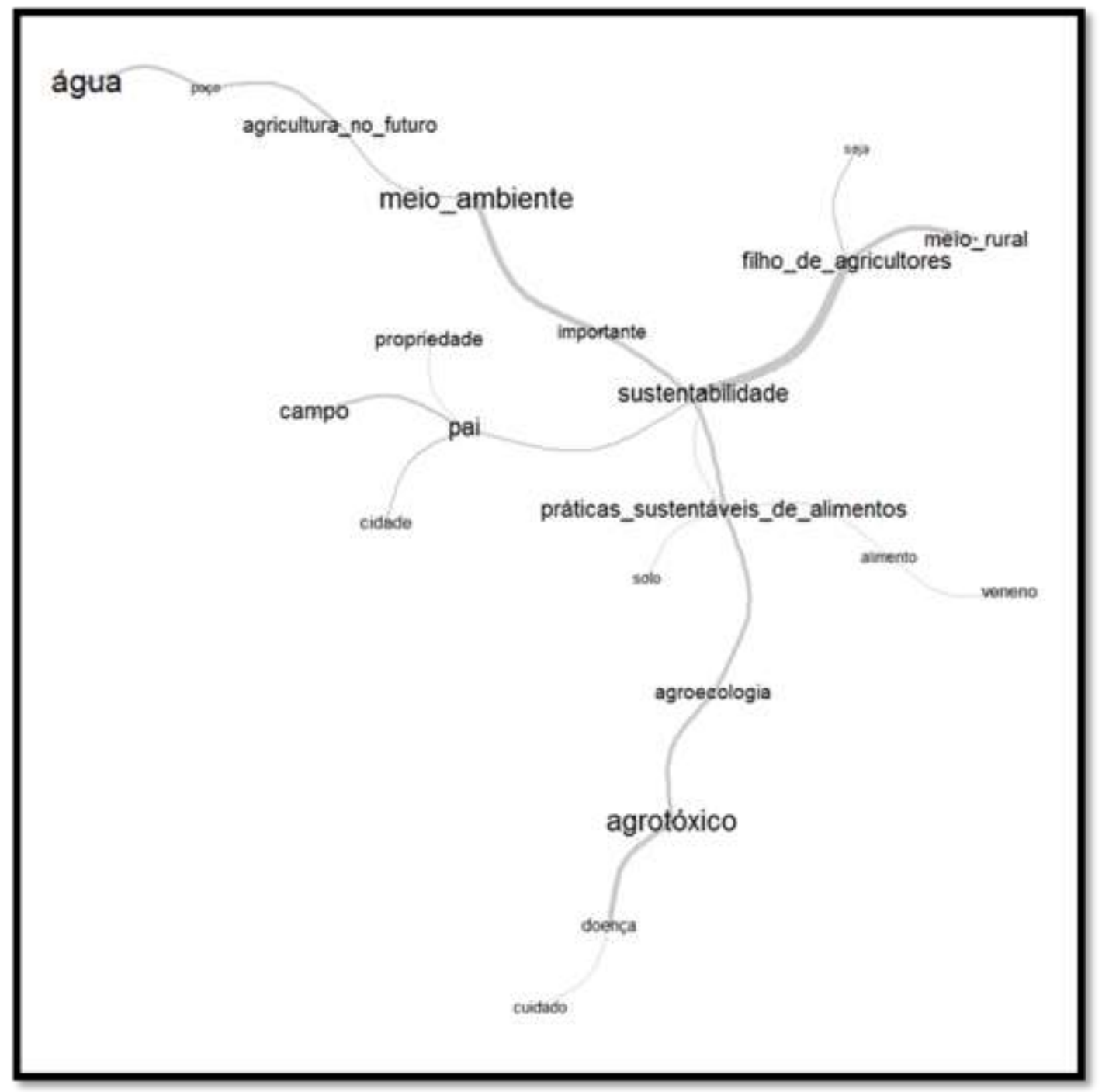

Fonte: Elaborado pelos autores com base no software IRaMuTeQ - (2018). 
Figura 3 - Gráfico da análise de similitude da E.M.E.F. Joaquim Nabuco.

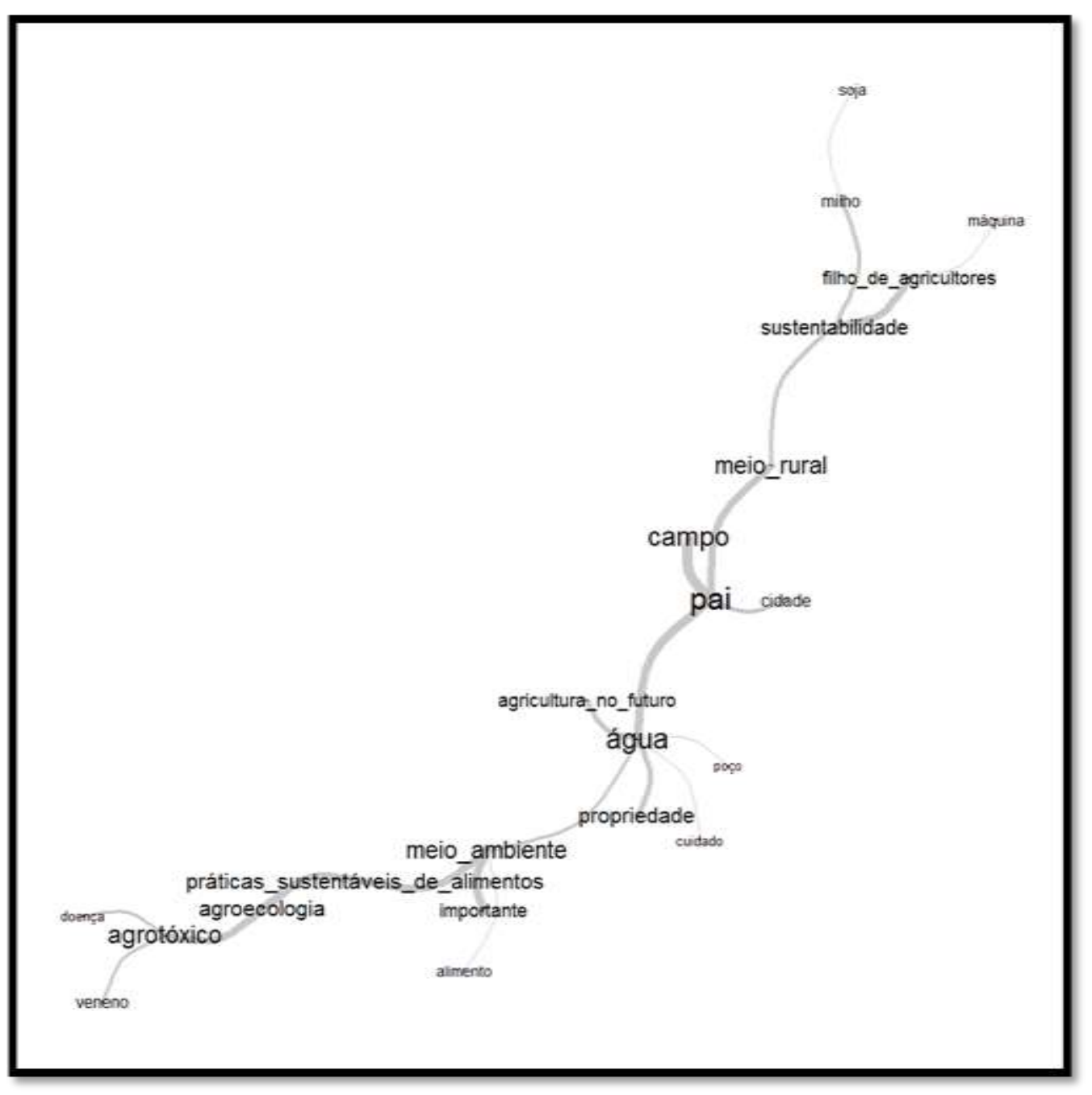

Fonte: Organizado pelos autores com base no software IRaMuTeQ - (2018).

A análise de similitude das Figuras 2 e 3 ou de semelhanças que é ancorada na teoria dos grafos, que constitui um modelo matemático ideal para quando se deseja estudar as relações entre objetos discretos de qualquer tipo e ainda permite identificar ocorrências entre o resultado e as palavras, trazendo a conexão entre os vocabulários que auxilia na identificação da estrutura de um corpus textual, diferenciando ainda as partes comuns e as especificidades em função das variáveis ilustrativas (descritivas) encontradas na análise.

Para a análise da relação existente entre as palavras e a sua conectividade dentro de cada classe foi feita a análise de semelhança. Com essa análise conseguiu-se perceber como os estudantes relacionam as várias palavras para descreverem seus conhecimentos em práticas agrícolas e a percepção ambiental relacionado a importância do meio ambiente e ao uso dos agrotóxicos.

Quanto a interligação de uma palavra com a outra, se dá pela sua associação entre uma a outra palavra presente no mesmo segmento. Verificou-se na (Figura 2) referente a E.E.E.F. Santana que as palavras de maior destaque e por consequência de maiores frequências foram: meio ambiente, agrotóxico e água. É preciso constatar que cada segmento precisa ser tratado separadamente, ou seja, um vocábulo de maior frequência num segmento poderá não ser o mesmo de destaque em um outro segmento. As distâncias de uma palavra com a outra podem ser também interpretadas; pode-se observar que a palavra "agrotóxico" está posicionado distantemente da palavra "sustentabilidade", bem como a de "meio ambiente", mesmo 
sendo pertencentes ao mesmo segmento. Portanto, a proximidade ou o distanciamento de uma palavra para com outra se dá pela sua similitude ou pela sua contradição (Camargo, 2005).

Ainda neste âmbito, a análise de similitude além de se basear nos grafos, é um tipo de análise que permite a identificação das ocorrências entre as palavras e seu resultado traz conexão entre as palavras, auxiliando desta forma na identificação da estrutura de um corpus textual, onde partes comuns e as especificidades são distinguidas em virtude das variáveis ilustrativas (descritivas) identificadas na análise (Marchand \& Ratinaud, 2012).

Ainda se tratando da análise da (Figura 2), ou seja, a da E.E.E.F. Santana em cada eixo nota-se que ao redor da palavra que se destacou vem outras palavras representadas que tiveram menor frequência, mas que tem articulações com a palavra de maior frequência. No eixo em que a palavra "agrotóxico" apresentou destaque, obteve-se as de menor destaque: agroecologia, doença e cuidado, ou seja, uma está associada a ocorrência da outra. Agrotóxico no sentido de representar algo prejudicial à saúde; agroecologia interligado ao cuidado ao solo sem o uso dos agrotóxicos, e a promoção de saúde por exemplo.

Em um outro eixo do grafo, a palavra de maior frequência foi: "práticas sustentáveis de alimentos"; rodeadas de palavras de menores frequências: solo, alimento e veneno. As interligações destas justifica a importância do solo para a produção de alimentos, uma vez que se emprega práticas sustentáveis de alimentos, não se utilizará produtos químicos convencionais; tal fato pode ser observado na fala de um participante 0 da pesquisa:

"[...] pra mim produção sustentável de alimentos é tu cuidar bem do seu solo adubando com esterco de animais porque assim vai conseguir planta alimentos sem agrotóxico" - Entrevistado 11 da E.E.E.F. Santana).

Numa outra zona periférica as palavras "sustentabilidade" e "filhos de agricultores" apresentaram maior frequência. No mesmo segmento estiveram posicionadas palavras de menores frequências, tais como: soja e meio rural, ligadas diretamente a palavra filhos de agricultores, deduzindo-se o cultivo das espécies, local de moradia e se são filhos de agricultores; já as palavras propriedade, campo e cidade estiveram interligadas diretamente com a palavra pai, o que se pressupõe o ato de liderança como quem cuida da propriedade e de quem parte a decisão de permanência no campo ou não. Salienta-se ainda que o termo sustentabilidade se manteve localizado ao centro, permanecendo interligado ao termo meio ambiente.

Em relação a (Figura 3) da análise referente a E.M.E.F. Joaquim Nabuco, as palavras de maior destaque e por consequência de maiores frequências foram: pai e água; seguidas das palavras agrotóxico, campo e meio rural. Mais uma vez pode-se verificar o distanciamento do vocábulo "agrotóxico" do vocábulo "sustentabilidade". Já na figura mencionada, a palavra "agrotóxico" se destacou um pouco menos quanto a da figura anterior. Tal realidade pode ser interpretada por exemplo, como menor índice de casos de intoxicação por uso deste na E.M.E.F. Joaquim Nabuco, pois não houve nenhum relato de doença pelo efeito dos produtos químicos entre os entrevistados; enquanto que na escola anterior como visto ocorreu a menção de dois casos de intoxicação pelo uso de agrotóxico.

Pelo destaque do vocábulo "pai" entende-se pelo mesmo ser direcionado como a liderança da propriedade rural; bem como quem toma as decisões e administra a lavoura. É importante ressaltar que tal vocábulo nas duas escolas apresentou interligações com o termos cidade e campo, confirmando mais uma vez o ato de liderança. Outra justificativa se dá pelo cunho familiar, pois nesta escola todos os alunos participantes moram com seus pais; o que também difere da escola anterior, onde nem todos os alunos residem com o pai e a mãe. Quanto a palavra "agrotóxico" também se manteve interligada a "doença" e "veneno", embora alguns mencionar que na sua propriedade fazem o uso, mas não foi encontrado nas entrevistas nenhuma ocorrência de danos à saúde.

É conhecido que quando se trata da aplicação de agrotóxico muitos dos agricultores conhecem os riscos e danos à saúde que podem provocar. Mesmo assim, muitos deles não respeitam o intervalo de reentrada nas lavouras e em muito dos 
casos não usam os Equipamentos de Proteção Individual (EPI) que tem por funcionalidade reduzir a incidência de riscos à saúde (Veiga et al., 2006, Londres, 2011). Dentre doenças causadas são afetados a pele, os olhos e o trato respiratório como também manifestações crônicas: doenças mentais, neurológicas, hepáticas e renais, destacando o câncer (Londres \& Souza et al., 2011, Carneiro et al., 2015).

Sobretudo, os agricultores buscam cada vez mais o aumento da sua produção o que muitas das vezes não caminham ao lado da sustentabilidade. Se verifica que a lucratividade tem se sobreposto a preservação e respeito ao meio ambiente. Os agricultores precisam buscar meios de garantir a produção de alimentos para que possam exercer uma atividade lucrativa, mas que também possam retribuir maior responsabilidade a respeito da manutenção e preservação dos recursos naturais, além da segurança alimentar. Cabe também ao Estado oferecer informações acerca dos efeitos na saúde, através da educação e por orientação técnica, por exemplo, pois se o Estado permite uma lei tão permissiva de uso de agrotóxicos, a culpa não pode recair somente no agricultor. Com isso, a Agroecologia vem preconizando a diversificação das culturas, promovendo uma ampla variedade de alimentos para a família, o que induz a uma melhoria na qualidade da alimentação delas (Warmling, 2013).

\section{Considerações Finais}

A pesquisa sobre a percepção ambiental dos atores mostra que a realidade de cada indivíduo, região, muda de acordo com a realidade vivenciada dos educandos. Nesse estudo, constatou-se que os estudantes estão cientes da existência dos recursos naturais presentes no local onde vivem, relatam a preservação dos recursos hídricos que abastecem as propriedades e a importância de preservar as nascentes, assim como não praticar desmatamentos e queimadas. Os mesmos destacaram a importância do solo e sua cobertura para a manutenção das plantas e redução do processo de erosão. Acreditam que o futuro da agricultura tenderá ser mais mecanizada e que aumentará o uso dos agroquímicos e as monoculturas. Na percepção de muitos, no campo predominará, no futuro, somente os grandes proprietários de terras e os menores migrarão para a zona urbana. Ao perceber esse espaço como algo negativo, as crianças podem estar construindo menos possibilidades de afeição do que permanência e transformação. Sem uma efetiva intervenção educacional, o aumento à depreciação ambiental e social das pessoas que estão submetidas a esse espaço poderá ocorrer.

Os resultados deste estudo demonstraram a relevância de trabalhar a Educação Ambiental de acordo com a realidade escolar. Para início, é importante começar a trabalhar com os alunos os conceitos mais básicos de conservação; pois além de ajudar na percepção, pode servir para induzi-los a mudanças. Vários alunos demostraram interesse em conhecer mais sobre o estudo do meio ambiente, porém embora eles conheçam os efeitos maléficos dos agrotóxicos sobre o ambiente e a saúde humana, eles precisam passar por uma aprendizagem que aborde de maneira mais eloquente as temáticas ambientais Pode-se notar nos questionários a dificuldade de muitos alunos ao dizerem o que sabiam sobre Agroecologia. No entanto, a agroecologia poderia ser abordada dentro da disciplina de Educação Ambiental ou em Ciências, nos temas relacionados com a produção de alimentos sustentáveis. Pereira Junior e Campos (2018) destacaram que existem carências na aplicação de práticas efetivas dos conceitos de preservação ambiental em escolas de Marabá - PA.

Outro fator importante e essencial é criar novas temáticas na escola que venham contribuir para a permanência do jovem no campo. Quanto a questão de gênero, a mulher precisa ser reconhecida, bem como valorizada por desempenhar funções como trabalhadora rural, e não necessariamente apenas o cuidado com os filhos e a casa. De acordo com Silva (2019), a mulher é vista como coadjuvante, sem reconhecimento dos seus incrementos no labor além das atividades domésticas e da responsabilidade de reprodução. Este é um conceito entranhado historicamente que anula em muitos casos o reconhecimento da mulher como parte importante e produtiva das atividades que geram renda. A desigualdade de gênero ainda é clara e evidente no meio rural e se mantém, inclusive, na divisão sexual das responsabilidades de trabalho, o que dificulta o reconhecimento da mulher como trabalhadora rural. 
Embora aborde apenas alguns aspectos ambientais, portanto é limitado, mas permite verificar a distância da educação formal do ambiente de vivência destes jovens e o descaso com o rural. A partir de suas percepções, verifica-se a necessidade de aproximação da Escola na discussão de temáticas ambientais onde o jovem se sinta parte, e que desta forma se tornem protagonistas das mudanças e da preservação ambiental.

Por fim, sugere-se para futuras pesquisas a ampliação da difusão dos conceitos agroecológicos de cultivos e da importância da agricultura familiar para a produção de alimentos. Este contexto apresenta importância principalmente em escolas, para que os preceitos de sustentabilidade ambiental, social e econômica sejam discutidos durante a formação das crianças e adolescentes com o intuito de afirmar a necessidade da preservação ambiental nos sistemas de produção de alimento, bem como, da transição de monocultivos com uso intensivo de agroquímicos para sistemas de policultivos com enfoque na preservação e no uso racional de protetores de produtividade.

\section{Referências}

Altieri, M. (2012). Agroecologia: bases científicas para uma agricultura sustentável. (3a ed.), AS/PTA.

Agência Nacional de Vigilância Sanitária - ANVISA. (2011). Cartilha Sobre Agrotóxico: Série Trilhas do Campo. http://portal.anvisa.gov.br/wps/wcm/connect/9e0b790048bc49b0a4f2af9a6e94f0d0/Cartilha.pd f?MOD=AJPERES

Brandalise, L. T. (2009). A percepção e o comportamento ambiental dos universitários em relação ao grau de educação ambiental. Gestão da Produção, 16(2), $273-285$.

Brandemburg, A. (2010). Do rural tradicional ao rural socioambiental. Ambiente e Sociedade, 13(2), 417-428.

Brasil. (2013). Secretaria de Políticas para as Mulheres. Plano Nacional de Políticas para as Mulheres. Brasília: Secretaria de Políticas para as Mulheres, 2013. http://www.compromissoeatitude.org.br/wp-content/uploads/2012/08/SPM_PNPM_2013.pdf

Brumer, A., \& Spanevello, R. M. (2008). Jovens agricultores da Região Sul do Brasil. Porto Alegre e Chapecó: UFRGS e FetrafSul/CUT. Relatório de Pesquisa.

Caramello, G. W. (2012). Aspectos da complexidade: contribuições da Física para compreensão do tema ambiental. $2012.250 \mathrm{f}$. Tese (Doutorado em Ensino de Ciências) - Programa de Pós-Graduação do Instituto de Física e da Faculdade de Educação da Universidade de São Paulo, São Paulo.

Carneiro, M. J., \& Castro, E. G. (2007). (orgs.). Juventude rural em perspectiva. Mauad X.

Carneiro, F. F., Rigotto, R. M., Augusto, L. G. S., Friedrich, K., \& Búrigo, A. C. (2015). Dossiê ABRASCO: Um alerta sobre os impactos dos agrotóxicos na saúde. Rio de Janeiro: EPSJV; Expressão Popular.

Chartier, J. F., \& Meunier, J. G. (2011). Text mining methods for social representation analysis in Large Corpora. Papers on Social Representations, 20(37), 147,2011 .

Cristofoli, L. (2012). Mineração de Textos Baseada em Algoritmos Imunológicos. Caxias do Sul.

Cruz, B. A. (2014). Perfil nutricional de trabalhadores rurais de grandes áreas de uma produção agrícola da cidade de Unaí $\neg$ MG. 2014. Trabalho de Conclusão de Curso (Faculdade de Ciências da Educação e Saúde) - Centro Universitário de Brasília - Uniceubᄀ, Brasília.

Dalcin, D., \& Troian, A. (2009). Jovem no meio rural a dicotomia entre sair e permanecer: um estudo de caso. In: Seminário Nacional Sociologia \& Política, 1, 2009, Curitiba. Anais eletrônicos... Curitiba: Sociedade e Política em tempos de Incerteza. http://www.humanas.ufpr.br/site/evento/SociologiaPolitica/GTsONLINE/GT7\%20online/jovem-meio-rural-DioneiaDalcin.pdf

Espíndola, E. A. (2011). Análise da percepção de risco do uso de agrotóxicos em áreas rurais: um estudo junto aos agricultores no município de Bom Repouso (MG). 2011. 155 f. Tese (Doutorado em Ciências da Engenharia Ambiental) - Universidade de São Paulo, São Carlos. http://www.teses.usp.br/teses/disponiveis/18/18139/tde-09062011-152841/pt-br.php

Feix, R. D., \& Leusin Júnior, S. (2015). Painel do agronegócio no Rio Grande do Sul - 2015. Painel do Agronegócio no Rio Grande do Sul. FEE. p. 1-44.

Fernandes, R. S., \& Pelissari, V. B. (2003). Como os jovens percebem as questões ambientais. Revista Aprender, 13(4), 10-15.

Figueiredo, J. B. A. (2007). Educação ambiental dialógica: as contribuições de Paulo Freire e a cultura sertaneja nordestina. Fortaleza: Edições UFC. 392 p.

Freire, N. (2010). Ações governamentais para os direitos das mulheres. In: Direitos humanos como direitos de todos, sem exceção. Ribeiro, M. (Org.). São Paulo: editora Fundação Perseu Abramo.

Gomes, P. R., \& Malheiros, T. F. (2012). Proposta de Análise de Indicadores Ambientais para Apoio na Discussão da Sustentabilidade. Revista Brasileira de Gestão e Desenvolvimento Regional, 8(2), 151-169.

Hirata, H. (2010). Novas configurações da divisão sexual do trabalho. Revista Tecnologia e Sociedade, 6(11), 1-7. 
Ibama. (2016). Boletins anuais de produção, importação, exportação e vendas de agrotóxicos no Brasil. http://www.ibama.gov.br/phocadownload/qualidade_ambiental/relatorios/2014/os_dez_ias_ve ndidos_2014.xls

Klemann, M., Reategui, E., \& Rapkiewicz, C. (2011). Análise de Ferramentas de Mineração de Textos para Apoio à Produção Textual.

Koche, J. C. (2011). Fundamentos de metodologia científica. Vozes.

Lahlou, S. (2012). Text mining methods: An answer to Chartier and Meunier. Papers on Social Representations, 20(38), 1-7. http://eprints.1se.ac.uk/46728/1/Text\%20mining\%20methods(1sero).pdf

Leccadi, C. (2010). La juventude, el cambio social y la família: de una cultura “de protección” a una cultura "de negociación”. In: Mínguez, A. M. (Coord.). Juventud Y FAMILIA DESDE UMA PERSPECTIVA comparada europea. Revista de Estudos de Juventud, 10(90), 33-42.

Lellis, M. H. M., Bufalo, F. S., Oliveira, M. A. F. M., \& Mura, G. R. (2016). Agrotóxicos na Produção de Alimentos: Consequências e Alternativas. Jornal Biosferas.

Londres, F. (2011). Agrotóxicos no Brasil: um guia para ação em defesa da vida. AS-PTA - Assessoria e Serviços a Projetos em Agricultura Alternativa: Rio de Janeiro.

Lovatto, P. B., Etges, V. E., \& Karnopp, E. (2008). A natureza na percepção dos agricultores familiares do município de Santa Cruz do Sul, RS, Brasil: algumas perspectivas para o Desenvolvimento Regional Sustentável. REDES, 13(1), 225-249. http://online.unisc.br/seer/index.php/redes/article/view/321/1487

Lucena, M. M. A. (2010). Percepção ambiental por uma comunidade rural do entorno de uma reserva particular do patrimônio natural (RPPN), semiárido brasileiro. 2010. 71 f. Dissertação (Mestrado em Desenvolvimento e Meio Ambiente) - Universidade Federal do Rio Grande do Norte, Natal. ftp://ufrn.br/pub/biblioteca/ext/bdtd/MycarlaMAL_DISSERT.pdf

Marchand, P., \& Ratinaud, P. (2012). L'analyse de similitude appliqueé aux corpus textueles: les primaires socialistes pour l'election présidentielle française. 2012. In: Actes des 11eme Journées internationales d'Analyse statistique des Données Textuelles. JADT, p. 687-699. Liège, Belgique. from http://lexicometrica.univparis3.fr/jadt/jadt2012/Communications/Marchand,\%20Pascal\%20et\%20al.\%20\%20L\%27analyse\%20de\%20similitude\%20appliquee $\% 20$ aux\%20corpus\%20textuels.pdf

Oliveira, M. F., Mendes, L., \& Vasconcelos, A. C. V. H. (2021). Desafios àpermanência do jovem no meio rural: um estudo de casos em Piracicaba-SP e Uberlândia-MG. Revista de Economia e Sociologia Rural, 59(2), e222727.

Pereira Junior, A., Campos, R. A. S. (2018). Análise comparativa das práticas ambientais utilizadas no ensino da educação ambientalem escolas públicas. Revista Brasileira de Educação Ambiental, 13(1), 364-386.

Rebelo, R. M., \& Caldas, E. D. (2014). Avaliação de risco ambiental de ambientes aquáticos afetados pelo uso de agrotóxicos. Química Nova, 37, 1199-1208.

Silva, M. R. (2019). Gênero, desigualdades e agricultura: a mulher na atividade agrícola familiar. Brazilian Journal of Development, 5(3), $2095-2105$.

Silva, J. C., Zini, L. B., \& Garibotti, V. (2016). Resíduos de Agrotóxicos na Água para Consumo Humano no Rio Grande do Sul. Boletim Epidemiológico do Centro Estadual de Vigilância em Saúde do Rio Grande do Sul, 18(1-2).

Teixeira, J. C. (2005). Modernização da agricultura no brasil: impactos econômicos, sociais e ambientais. Revista Eletrônica da Associação dos Geógrafos Brasileiros, 2(2), 21-42.

Tilden, F. (1967). Interpreting our Heritage.[S.I.] University of North Carolina Press.

Vasco, A. P., \& Zakrzevski, S. B. B. (2010). O estado da arte das pesquisas sobre percepção ambiental no Brasil. Perspectiva, 34(125), 17-28.

Veiga, M. M., Silva, D. M., Veiga, L. B. E., \& Faria, M. V. C. (2006). Análise da contaminação dos sistemas hídricos por agrotóxicos numa pequena comunidade rural do Sudeste do Brasil. Cadernos de Saúde Pública, 22(11), p. 2391-2399.

Veiga, M. M. (2007). Agrotóxicos: eficiência econômica e injustiça socioambiental. Ciência e Saúde Coletiva, 12(1), $145-152$.

Warmling, D. (2013). O discurso da agroecologia para a promoção da saúde: uma perspectiva construcionista social. Saúde \& Transformação Social / Health \& Social Change, 4(4), 1-2.

Wommer, D. H., \& Cassol, C. V. (2014). A participação Feminina na Gestão da Propriedade Rural: cuidado que qualifica e humani za. In: COTRIN, Décio (Org). Desenvolvimento rural e agricultura familiar. 3. 469-493. E-book. http://www.emater.tche.br/site/arquivos_pdf/teses/E_Book3.pdf

Zini, L. B. (2016). Contaminação de agrotóxicos na água para consumo humano no RS: avaliação de riscos, desenvolvimento e validação de método empregando SPE e LC-MS/MS. 2016. 133 f. Dissertação (Mestrado em Engenharia Química) - Universidade Federal do Rio Grande do Sul. 